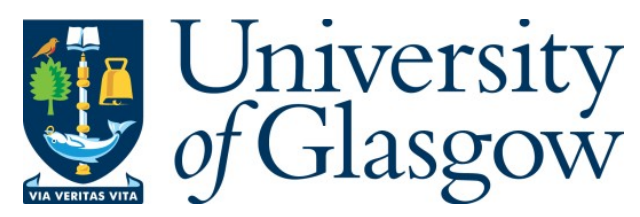

Hughes-Hallett, M., Young, C. and Messier, P. (2021) A review of RTI and an investigation into the applicability of micro-RTI as a tool for the documentation and conservation of modern and contemporary paintings. Journal of the American Institute for Conservation, 60(1), pp. 18-31.

(doi: $\underline{10.1080 / 01971360.2019 .1700724)}$

This is the Author Accepted Manuscript.

There may be differences between this version and the published version. You are advised to consult the publisher's version if you wish to cite from it.

https://eprints.gla.ac.uk/213121/

Deposited on: 21 May 2020

Enlighten - Research publications by members of the University of Glasgow http://eprints.gla.ac.uk 


\title{
A review of RTI and an investigation into the Applicability of Mi- cro-RTI as a Tool for the Documentation and Conservation of Modern and Contemporary Paintings
}

\author{
Molly Hughes-Hallett, Hamilton-Kerr Institute, University of Cambridge \\ Christina Young, Technical Art History Group, College of Arts, University of Glasgow.
Paul Messier, Lens Media Lab, Institute for the Preservation of Cultural Heritage, Yale University.

Key words: Reflectance Transformation Imaging, RTI, Dome, Modern, Contemporary, Surface Texture, Micro-RTI, Laser scanning, Paintings

\begin{abstract}
Reflectance Transformation Imaging (RTI) is a non-invasive method of examination which can be used to document and visualize the surface texture of objects, including artworks. Through imaging an object under different directions of illumination, topographical maps of a low relief surface can be produced, which when further processed can be used as an interactive visual aid. This paper summaries the current state of research on micro-RTI, and presents an investigation into a micro-RTI system comprised of a digital microscope and miniature lighting array dome, which was originally developed to study small areas of surface texture. The article reviews the techniques required to adequately use the micro-RTI, and evaluates the system's use as a practical tool for conserving and documenting modern and contemporary easel paintings. This was determined by evaluating its data processing, ability to accurately document test panels and case study paintings, and comparing it with alternative documentation methods of standard microscopy and laser scanning. It was found that micro-RTI is a useful tool for modern and contemporary paintings and their often complex and/or delicate surfaces, where subtle surface alterations can result in visually distracting features.
\end{abstract}

\section{Introduction}

An investigation was conducted into the applicability of a Reflectance Transformation Imaging system (RTI) to document and study surface textures of modern and contemporary paintings. This is particularly relevant for cases where texture is paramount to the final aesthetic of the work. The limitations and advantages of the technique were evaluated from the perspective of being a practical and useful tool for conservators, aiding both in documentation and conservation.

The scope of the research was focused on the investigation of modern and contemporary paintings as they are often challenging for conservators both in treatment and documentation. Their features can include broad areas of a single color (e.g. color field paintings) with matt or highly reflective surfaces, which are easily disrupted by small surface deformations or flaws. The combination of unconventional modern paint materials can make these works difficult to treat, while photography of the entire painting often fails to sufficiently capture subtle textural issues which the human eye can detect.

RTI is a non-invasive method of examination which has the advantage of highlighting surface texture and low relief curvatures of objects. RTI can reveal surface information that is usually not possible to record via conventional methods of documentation. This investigation primarily 
focuses on the micro-RTI system developed using a digital microscope to study surface textures in detail over small areas (Messier et al. 2013). Case studies include paintings from the Yale University Art Gallery, the Courtauld Institute of Art, and privately owned works undergoing conservation treatment. Control samples tested the parameters and performance of the micro-RTI system to assess its effectiveness for conservation treatments; a comparison study of laser scanning of the control panels as well as standard microscopy was also carried out.

\section{Reflectance Transformation Imaging (RTI)}

RTI is a computational photographic method; using computer algorithms, it extracts relevant information from a sequence of digital photographs which is integrated into a new digital representation (in this case the RTI file) in order to present surface geometry data not available from a single photograph (CHI. 2014). Through the mathematical enhancement of the object's texture and color, the RTI software can reveal surface information that is not apparent with visual empirical examination of the physical object. The ability to create virtual lighting conditions allows for post examination away from the object.

The object is sequentially imaged under illumination from different angles. From these images a mathematically synthesized interactive map of the surface is produced. The key components to produce an RTI file are a camera in a known capture position perpendicular to the surface, and a series of known light positions. The RTI file differs from a conventional photograph in that the reflectance data is extracted from the image and encoded. Each RTI file capture is created from 2-dimensional digital images. The reconstructed RTI file is used to accurately reproduce the direction that the light reflects from a surface of the object dependent on it incident direction. This is achieved by recording the RGBN (red-green-blue- and 'normal') values for each pixel.

A 'normal' is a vector that is perpendicular to the tangent plane at any point on an object's surface (Figure 1). Specular reflection takes place on a optically smooth surface; when light scatters from the surface, the incident and reflected angles of the light are both at equal angles to the surface normal (Figure 2a). If the surface is optically rough (surface roughness on the same order of magnitude as the wavelength of illumination), the normal vector at the point of incidence varies across the surface, deflecting the light rays in many directions (Figure 2b).

\subsection{RTI Applications with Cultural Heritage}

As a relatively new imaging technique, RTI's genesis dates from 2000 with Tom Malzbender et al. of Hewlett Packard (HP) Labs, who originally developed it for 3D rendering in computer games. RTI was introduced as a system based on the characterization of surface reflectance properties to achieve photorealistic renderings (Malzbender, Gelb and Wolters 2001). Initially, RTI was primarily adapted to study objects or works in relief, such as Egyptian hieroglyphs, and continues to be popular in Egyptology (Mudge et al. 2010; Abdrabou et al. 2017). These earlier studies explored relatively large changes in surface texture, in contrast to the subtle changes investigated in this paper. A preliminary study of painting texture was conducted by Padfield, Saunders and Malzbender in (2005) in which a prototype dome was constructed to image test paintings with strong impasto, in addition to selected paintings from the National Gallery, London. The research concluded that the system was controllable and reproducible, and could be useful in the examination of works going out on loan or undergoing structural treatment.

Despite the work conducted on RTI to date, institutions within the UK have not adopted RTI (Payne, 2012). There has been an initial study of the qualitative (and semi-quantitative) data that RTI can deliver, although none has been carried out using micro-RTI to date (Manfredi et 
al. 2014). Only recently has there been a study using RTI on a modern or contemporary painting. In 2017, Kolkena et al. utilized RTI in documenting an unpainted canvas work by Piero Manzoni which was finely textured with deliberate wrinkles and a machine stitched grid of seams (Kolkena et al. 2017). RTI was used to document the entire painting, and successfully recorded the subtle changes in the painting's matt surface. RTI revealed that stains on the canvas affected both the hue of the fibers as well as the surface texture. In the USA several institutions including the Smithsonian Institution, the New York Museum of Modern Art, the Metropolitan Museum of Art, the Fine Arts Museum of San Francisco, the Los Angeles County Museum of Art, and the Worcester Art Museum have experimented with RTI, although few have published their findings (Mudge et al. 2010). Emma Payne (2012) credits RTI developments in the USA to California based group Cultural Heritage Imaging (CHI), a non-profit organization dedicated to advancing the state of cultural heritage documentation. This is evidenced by their multiple publications on RTI research and hosting regular RTI training events for conservators at museums across the USA. In 2017, the Metropolitan Museum of Art held the first RTI symposium (Illumination of Material Culture: A Symposium on Computational Photography and Reflectance Transformation Imaging (RTI)), which brought together conservators and scientists developing the field for the first time.

RTI is not the only form of surface documentation available to the conservation community; several non-invasive techniques such as laser and structured light scanning, 3D microscopy and CT scanning have been adapted to conservation science. However issues with cost, size, speed, and complexity in visualizing and interpreting the final data may explain the lack of uptake in the conservation community. In comparison with other methods, micro-RTI has until now been under-investigated, and yet may offer a more specialized form of imaging compared to other forms of RTI. 3D microscopy has also started to be used in the conservation community, and while relevant and comparable to micro-RTI, it was not possible within the time and budget constraints of this project to compare this method, except to point out that such microscopy systems are less flexible for field work.

\subsection{RTI Configurations}

The most common RTI configurations are: the dome lighting array, highlight capture, and, the focus of this project, the micro-RTI dome (Figure 3). The dome lighting array is a hemispherical structured armature, supporting a series of tiered lights which are lit individually. In contrast, the highlight capture method creates a virtual dome using a portable light source, which is repositioned for each capture. Each system has advantages and disadvantages in terms of cost, portability, repeatability and ease of use.

The dome lighting array is the most expensive of the RTI set ups (roughly \$50,000 USD), and is compromised by its size. In the study by Padfield, Saunders and Malzbender (2005) at the National Gallery, the maximum painting dimensions was limited to $40 \times 40 \mathrm{~cm}$, while the dome armature exceeding a meter in diameter. This size limitation is significant when considering the documentation of modern and contemporary paintings, which generally tend to be large in scale. Moving an artwork in and out of the dome can also present issues, especially if the work is fragile or three dimensional.

The highlight capture method creates a virtual dome and was developed by CHI in 2006 (Mudge et al. 2006). With the camera and object kept stationary, a portable light source (CHI recommend a flash unit) is repositioned for a series of images lit from different angles creating a hemisphere of lighting samples around the photographed item (CHI, 2013). The benefits of this system in comparison to the dome lighting array are its portability, flexibility and low running cost. However the highlight method is more time-consuming, typically requires more 
space to manoeuvre around the object, and usually needs more than one person to operate the system (preferably someone with RTI capture experience). The manual aspect of the highlight method leaves room for human error, potentially causing problems with repeatability and data processing.

\subsection{The Micro-RTI System}

The micro-RTI is based on the dome lighting array format. The system used in this paper is comprised of 56 store bought LED lights arranged on four tiers around a $12 \mathrm{~cm}$ diameter dome. The micro-RTI dome is mounted on a tripod and is equipped with a focusing boom, lens, and a high resolution CCD camera connected via USB to a laptop (see Appendix for full specifications of the micro-RTI apparatus). The 56 LEDs produces a set of 56 images, each illuminated by a single LED.

The advantage of the small system is that it focuses on a specific area, such as a retouching or a scratch, without the need to gather, process and store data for the entire painting. It is portable, can be operated by one person, and can be used vertically or horizontally - in contrast to larger domes which must be horizontal due to their heavy structure. There are four micro-RTI domes of this design (built by Paul Messier), owned by: the Metropolitan Museum of Art, the Library of Congress, the Rijksmuseum and Yale University. The entire system costs \$15,000 USD making it more expensive than the highlight method, but still a relatively low cost method of examination. To the authors' knowledge, no studies on the applicability of the micro-RTI system on painted surfaces have been conducted.

The micro-RTI system uses three forms of software to create and view the final project. Having to swap between software packages is slightly unwieldy, however the entire process for one capture sequence takes a mere 15 minutes. The role of each is detailed below:

1. The data is collated via image capture software: Monkeybrain (Messier 2014). The fixed hardware angles and location of each light source, as well as the camera viewpoint, are written into the metadata needed for the rendering algorithms. Once aperture, focus and magnification are set, the micro-RTI system is automatic; the user simply presses a button to initiate the image capture for each LED position. A home file is automatically created, storing all the associated data for each image.

2. The RTI file is then built in RTIBuilder. The algorithms required to extract the information are embedded, thus keeping the process user-friendly.

3. The file is viewed in RTIViewer (the latter two software packages were developed by $\mathrm{CHI}$ as open source software and can be downloaded for free online, at http://culturalheritageimaging.org/What_We_Offer/Downloads/). The file can be opened by any device with the software, and has been used by museums wishing to create an interactive display for visitors (Mudge et al., 2010). The viewer has many control settings; it is possible to zoom, capture screenshots of the object under specific viewing parameters and rendering modes into jpeg images, and alter the light source angle via a mouse operated virtual light. These features can also be accessed by inputting specific coordinates, allowing for accurate side-by-side comparisons of extracted images. The software does not support comparing two RTI files simultaneously on one device. Given that RTI is used by conservators for monitoring surface change, this feature should be added in future updates. The user (e.g. a conservator) can use the RTIViewer to interactively reproduce the lighting at different illumination angles and enhance the object's texture and color within the software. There are 3 rendering modes within the RTIViewer software which aid the study of surface textures. 'Default' is the RTI image without mathematical enhancement, and resembles a standard color photograph with 
dynamic relighting capabilities (Figure 4a). A "normals visualization" creates a mapped visualization of the surface according to the normal vector for each pixel (Figure 4c). Normals maps are commonly stored as RGB images; the RGB components correspond to the $\mathrm{X}, \mathrm{Y}$, and $\mathrm{Z}$ coordinates of the surface normal, creating an illusion of depth. Specular enhancement extracts the reflectance function of the surface, then mathematically enhances the specular highlights computed from the surface normal (Figure 4b). This is useful in seeing surface specularity changes, or removing the distraction of color to see surface texture alone. Through these rendering modes, the user is able to explore the object and examine its surface on a screen, without the object itself necessarily needing to be physically present.

The majority of the software options for the RTI visualization are intuitive and do not require specialist knowledge of computing or optics. It has been visually compared to SEM imaging (in a related comparative study), which similarly can map a small surface sample in great detail. (Lauffenburger et al., 2015)

\section{Evaluation of the Micro-RTI System}

\subsection{System Variables}

The micro-RTI system is composed of several key variable components, which were assessed for reliability, functionality and repeatability. Optical variables including exposure, focus, aperture, magnification and LED wavelength were tested. A mid-tone grey card (Daler-Rowley: Canford Card in 'Gun Metal') was selected as a neutral control surface, and components were assessed using histograms generated in Image-J (open source image processing software) of the pixel greyscale values for a illumination angle perpendicular to the surface. A full analysis can be found at the on request at the Courtauld Institute of Art's library (Hughes-Hallett, 2016).

As for any optical imaging technique, the final image should be appropriately exposed and in focus. It was noted that exposure change does not significantly effect the final simulated object surface, for a range of exposure levels $(50-500 \mathrm{~ms})$. Exposure and focus were therefore both set case by case for optimum imaging results. Increasing the aperture decreases the vignetting and expands the field of view of the surface under investigation from approximately $5 \mathrm{~mm}$ to 26.5 $\mathrm{mm}$ in diameter. For color comparison (e.g. before and after retouching), a smaller aperture is beneficial as it creates a more uniform brightness. A mid to high aperture setting was used for most tests to minimise the vignetting.

The evaluation of the software and imaging process concluded that minor adjustments could streamline this form of analysis, and make it even more simple for the user. The micro-RTI would hugely benefit from an inbuilt scale bar, and ideally the three different softwares could be streamlined into a single integrated software package including the set-up, acquisition, rendering and viewing. The quantification of RTI data continues to be unresolved, and should be investigated and developed in the future.

The following overwhelmingly positive observations could be made about operating the microRTI. The hardware is easily portable and compact, and can be stored away to take up minimal space and is easily to transport for use in-situ. The system is quick and simple to assemble, and the overall imaging and processing time is fast (15 minutes for capture and RTI file processing). The software is free and the RTI files are easily shared.

\subsection{Test panels}


The applicability of the micro-RTI setup was assessed through the study of test panels and a selection of modern and contemporary case study paintings. A series of three reconstructions with surface features/textures that may be found in modern and contemporary paintings were used to ascertain what could be identified by the micro-RTI. These included smooth sprayed paint, under bound acrylic paint and straight edge boundaries created by masking tape. Detailed analysis of all paintings and test panels documented is available in an unpublished research thesis, with the most illustrative examples described below (Hughes-Hallett, 2016). The technique of laser scanning was also used to compare the level of detail that the micro-RTI could detect compared to a technique frequently applied to paintings (Factum Arte, 2015).

A set of test panels previously made for student workshops were ideal candidates for simulating features of interest. These panels were acrylic pre-primed canvas boards, with areas of underbound ultramarine pigment in PVA, and areas of matt sprayed pigment in a solvent based acrylic media. Additional features included scrapes, dirt accumulation, attempted surface cleaning and retouchings.

Test panel 1 was used investigate the ability of the micro-RTI system to document an area of dusty, friable pigment which was under-bound in PVA medium. This test panel was used to compare the Micro-RTI to comparative images taken with a standard microscope (a Leica M165C). Figure 5a, was taken using both moveable arm lights to illuminate the surface from both directions. Figure $5 \mathrm{~b}$ was taken with illumination at a raking angle of roughly $45^{\circ}$ from the left. Figure $5 \mathrm{c}$ was taken illuminated using the fixed angled bar light positioned at $20^{\circ}$ to the surface, used by Paul Messier to document surface textures in other projects (Messier et al. 2013). The three images recorded under the microscope revealed considerably less information than the RTI file (figure 6). The RTI in default mode reveals comparatively similar information to the bar light image; however, in specular and normals visualization modes the topography of the pigment is more defined, with a clearer resolution of the gritty quality. There is a clear change in level between the friable pigment layer and the ground below and, additionally, the flattened quality of the pigment is evident. This test confirmed that the RTI can provide further detail for a diffuse surface than the flatter result delivered by conventional imaging methods.

Test panel 2 was used to judge how the RTI would document retouching. The panel included straight edge boundaries between blue and white paint passages, created by applying masking tape before the blue paint was applied. The white was the canvas board's pre-applied commercial acrylic gesso, while the blue was sprayed pigment in a solvent based acrylic media. Imaging focused on a scrape on the paint surface of test panel 2, which is $2 \mathrm{~cm}$ long across both blue and white passages. RTIs of test panel 2 were created before and after retouching for comparison (figure 7). The scratch was retouched using Paraloid B72 loose pigment and Paraloid B72 retouching gels to aid in rebuilding the canvas texture. While effective, the retouching was still visible to the naked eye, and the textural difference was visible in both specular and normals visualization. This test demonstrated that the RTI could be useful for identifying textural issues prior to and during treatment.

Similarly to Test panel 2, Test panel 3 had a masked boundary between a blue acrylic sprayed paint passage and the white acrylic gesso, which were separated by a straight edge created with the help of masking tape. The blue paint had leaked under the masking tape, causing an uneven edge.

During the course of the research it was possible to make an empirical comparison of the microRTI system with a laser scanner. While these two techniques are not directly comparable, they are ultimately both currently used within the cultural heritage field to document surface texture. The Lucida Scanner is manufactured by Factum Arte, which had recently been acquired by the 
National Gallery, London (see Appendix for instrument parameters). Using test panel 3, an area at the interface between two paint passages was scanned where the smattering of leaked blue paint over the straight edge was particularly prominent.

The area imaged by the micro-RTI was approximately $1.3 \mathrm{~cm}$ in diameter (figure 4), with a total capture and processing time of 15 minutes. The Lucida scanner recorded data from the test painting $(15 \mathrm{~cm} \times 22 \mathrm{~cm})$ in one scan in approximately 20 minutes, however this did not include the post processing which took approximately two hours. The post processed data from the Lucida Scanner was converted to an RTI file, to allow a direct comparison of the texture and feature detection of the two systems (Aure et al., 2017). The RTI image obtained from the Lucinda scanner did not contain the smattered blue paint that had leaked over the crisp edge (figure 8), which is clearly visible in the comparative renderings of the same area using microRTI. The laser scan comparison was at the highest quality setting, however, the micro-RTI system provided more useful local information with a higher resolution and higher magnification. The Lucida system was more laborious to set up, had longer data acquisition time, the final file was much larger and more cumbersome, while ultimately the image quality was poorer and provided less detail on a micro scale. While the Lucida system generally gathers more data on a wider scale and excelled at mapping larger areas of texture, the micro-RTI was more successful at looking at surface detail on a smaller localised area.

\section{Case Studies}

The micro-RTI was evaluated as a tool for practicing conservators, with reference to nine paintings (three of which are discussed below). Modern and contemporary paintings were chosen as they can present specific issues with subtle surface texture and features. Thus, RTI data might prove useful at visualizing these features, which relate to artist technique and conservation treatment. In most cases, the RTI provided valuable insights that illustrated an artist's technique, or provided the basis to make a decision towards the next phase of treatment.

\subsection{Friedrich Vordemberge-Gildewart's Composition No. 135}

Composition No. 135 by Friedrich Vordemberge-Gildewart (1942, Oil on canvas, 54 x $74 \mathrm{~cm}$ ) in the Yale University Art Gallery collection, is an abstract painting which exemplifies some of the surface variations of modern art (figure 9). The painting was selectively varnished by the artist, creating a highly reflective black flat plane contrasting with minimal matt shapes and incision lines. This painting is an ideal candidate for assessing how the micro-RTI system images a surface which normally challenges conventional photographic methods.

The RTI acquisition focused on the boundary between the reflective black and matt pink areas (Figure 10). The normals rendering of the two regions effectively shows the difference in reflective qualities of the two paint surfaces. The reflectivity of the black extended to the boundary of the pink, demonstrating that the pink was in fact painted onto the black after the varnish had been applied. In addition, what appeared to be one incision line was actually three. Neither of these crucial observations involving the artist's technique were visible with conventional visual examination.

\subsection{Charles Parker's A Full Pavilion at the Surrey C.C.C The Oval}

The micro-RTI system was used in-situ at the Oval, Surrey County Cricket Club to examine $A$ Full Pavilion at the Surrey C.C.C by Charles Parker (1911) (figure 11). The micro-RTI proved to be simple to set-up and use in-situ on a large painting that was hung approximately 1.5 meters above floor level. A large scrape (approximately $2 \mathrm{~m}$ long and $1 \mathrm{~cm}$ wide) across the surface of the painting had been treated in-situ by private conservator Mary Bustin. However, 
she had observed that the scrape was still slightly visible in a certain light and it was hoped that RTI would be able to indicate why the damage had not been resolved, and whether the impact had affected the original paint layers.

RTI revealed that the scuff had broken the varnish and wax layers, and had effectively removed coating material. The varnish and wax layers were thick to the extent that surface texture, such as canvas weave and paint texture, had been smoothed. The RTI clearly showed that where the top coating had been reduced, the canvas weave was more prominent. In specular and normals visualization, a clear drop in surface level where the scrape has affected the surface is apparent (figure 12). The RTI also showed that the scrape has not affected original paint layers. In this case, the RTI analysis helped to re-evaluate the methods used to treat the scratch, the materials that would be most appropriate, and provided information regarding the level of damage.

\subsection{John Golding's Blue Predella}

Color field painting Blue Predella, by John Golding (1967, Acrylic on Canvas, 228.6 x 165.1 $\mathrm{cm}$ ), was also examined and treated as part of this research (figure 13). The painting had incurred damage in the form of two round indentations approximately $3 \mathrm{~cm}$ in diameter. No paint loss or tear had occurred, however it appeared that the acrylic paint surface had been burnished on impact thus changing the reflectance. The dents were visually distracting on the otherwise matt surface of this modern color field painting, however were treated successfully (figure 14).

In the before treatment RTI images of both dents (figure 15), the surface along the curved impact was visibly scraped and had disturbed the diffusion of incident light. Normals and specular visualization were able to show the change of surface angle caused by the dent and a clear demarcation of the curved rim of impact. It was difficult, however, to determine the severity of the dent, which was easier to ascertain without the RTI.

A comparison of the before and after treatment RTIs did reveal a change; the surface had become near level and evidence of the dent had visibly decreased (figure 16). While the RTI has shown a result, in this case it is not the most ideal method of analysis as its field was too small to register and evaluate the entire problem and remedy.

\section{Conclusions}

This research has shown that the micro-RTI system is not only applicable to the examination and conservation of paintings but can reveal information about a painting's surface that is detailed, descriptive and interactive. Micro-RTI provides a level of surface detail not attainable via conventional microscopy examination with a good field of view. Through this paper, the micro-RTI has been assessed based on its hardware and software's ease of use, and its degree of success in documenting common surface and reflectance problems exhibited by the test panels and case study paintings.

Unlike many examination techniques, the micro-RTI system does not require extensive training to operate and can be easily added into a conservator's range of examination tools. The hardware is compact, and can be stored away to take up minimal space. The system is quick and simple to assemble, and the overall imaging and processing time is fast (15 minutes for capture and RTI file processing). The software is free and the RTI files derived from other software are still compatible. Future research should pursue the quantification of the RTI data.

Case studies and test panels trials have indicated that the micro-RTI excelled at the documentation of specular dark surfaces, scratches, incisions, retouching and canvas weave, and could be applied successfully in the future to craquelure and impasto. The micro-RTI proved helpful in ongoing conservation projects; it provided information in-situ on paintings that were in need 
of treatment, and helped to evaluate the effectiveness of conservation work. The micro-RTI struggled to effectively document larger problems such as dents, as seen on Blue Predella. However, these problems lay primarily within the structure of the painting, instead of the painting's surface, and generally covered larger areas than the field of view possible using the microRTI and are more suited to conventional raking light photography. Microscopy and the Lucida scanner were used as comparable imaging techniques on test panels, and in both cases the micro-RTI was more successful in documenting a higher level of detail and information which proved to be more informative.

The micro-RTI is a useful tool for conservators in that it effectively extends our understanding of surface detail and nuances. The visual and qualitative character of the RTI makes it simple to interpret and can yield interesting results in the study of materials, techniques, and conservation treatments. In most cases, the RTI provided valuable insights that illustrated an artist's technique, or provided the basis to make a decision towards the next phase of treatment. RTI should also be used in tandem with established analysis tools, to yield more fruitful findings, while UK conservators should cooperate with American peers who have adapted and utilized this tool to their advantage. 


\section{Acknowledgements}

Cynthia Schwarz, Yale University Art Gallery

Mark Aronson, Yale Centre for British Art

Graeme Barraclough, Aviva Burnstock and Maureen Cross, Courtauld Institute of Art

Mary Bustin, Mary Bustin Ltd

Andrew Lane, Surrey County Cricket Club

Julia Nagle and Anna Cooper, Julia Nagle Conservation Ltd

Joseph Padfield, Xavier Aure Calvet and Rachel Billinge, The National Gallery, London

William Luckhurst and Diane Roth, Kings College, London

\section{Appendix: Instrument Specifications}

\section{Camera tripod:}

Manfrotto, 050 series

large tube diameters carbon fiber, three leg angles, geared mechanism for maximum precise settings

MT057C4-G

Maximum load: $12 \mathrm{~kg}$

Maximum height: $205 \mathrm{~cm}$

\section{Konova K5 Slider:}

Aluminium and steel camera smooth tracking rail

Slider length: $80 \mathrm{~cm}$

Maximum load: $23 \mathrm{~kg}$

\section{Micro RTI components:}

VZM Zoom Imaging Lense 200i Lense used for the RTI in all tests. Dials on lens

Edmund Optics Worldwide

Zoom ratio: $4: 1$

Magnification: $0.5-2 \mathrm{X}$

Manual Iris optional zoom lock. removable mounting flange

Primary Magnification With 0.5X Lens : Minimum 0.25X Maximum 1.0X

FOV (1/2" Horizontal Sensor)

$24.0 \mathrm{~mm} 6.0 \mathrm{~mm}$

Resolution in Object Space $10 \mathrm{lp} / \mathrm{mm} 40$ lp/mm

Resolution in Image Space 40 lp/mm 40 lp/mm

Working Distance $( \pm 3 \mathrm{~mm}) 152 \mathrm{~mm} 152 \mathrm{~mm}$

\section{Lt965RC Industrial and Scientific Camera}

Lumenera (camera) and Sony (sensor) Primary RTI camera. This USB 3.0 camera is ideal for applications where high resolution, and sensitivity are critical. Low noise electronics ensure clear and sharp images rendering details with accuracy.

Camera Interface: USB3.0

Resolution: 9.1 MP, 3376x 2704

Frame rate [fps]: 19

Sensor name: Sony ICX814 Quad tap

Sensor technology: CCD

Shutter type: Global

Pixel size $[\mu \mathrm{m}]: 3.69 \times 3.69$ 
Optical format: 1"

Exposure control: Manual and automatic

White Balance control: Manual and automatic

Dimensions: 43 x 43 x $65 \mathrm{~mm}$

Operating Temperature: 0 to $50 \mathrm{oC}$

Operating Humidity: 5 to $95 \%$, Non- condensing

Lens Mount: C-Mount

\section{Q501L Notebook PC}

Asus Laptop. Laptop used for RTI building and image capture

Processor: Intel ${ }^{\circledR}$ CoreTM i5 4200U

Operating system: Windows 8

Memory: DDR3L $1600 \mathrm{MHz}$ SDRAM, up to $8 \mathrm{G}$

Display: 15.6" 16:9 HD+ (1600x900)/

Full HD (1920x1080) anti-glare

Graphic: Integrated Intel® GMA 4500MHD

Dimensions: 383 x 255 × $22.3 \mathrm{~mm}$

Weight: $2.2 \mathrm{~kg}$

\section{Micro-Dome Lighting Array}

Micro Lighting Array constructed by Paul Messier.

56 LEDs.

Exterior Casing: $12 \times 12 \times 6 \mathrm{~cm}$.

Interior Dome diameter: $9.5 \mathrm{~cm}$.

\section{Rack and Pinion Focusing Mount}

Edmund, Model NT54-792

Focusing mount, used to soft focus and minorly adjust distance of the Micro-RTI from the painting. Fine and soft course focusing abilities.

\section{Lucida Structured Light Scanner}

Custom made by Factum Arte. Structured light scanner used at the National Gallery to provide comparative data, and quantitative data.

Laser diode Manufacturer and model: Laser Components ADL-65075TA 2

Cameras Manufacturer and model: IDS Imaging Development Systems UI-1221LE-M-GL

Microcontroller Chip manufacture and model: 8- bit Atmel AVR Atmega 328

Linear motion Manufacturer and model: Haydon Kerk RGS06

Laser Type: Auto Power Controlled Laser Diode. Stable light power output, compact size, high brightness laser light source.

Wavelength: $650 \mathrm{~nm}$

Power: $4 \mathrm{~mW}$

Cameras Type: Black \& White

Sensor: CMOS Mono by Aptina Imaging

Lens: Sunex DSL-300 EFL=17.1 f/4.2

Data transmission speed: $\max 25$

Mbytes/s per camera

Interface: USB 2.0

Resolution: 752 x 480 pixels

Microcontroller Clock speed: $16 \mathrm{MHz}$

Operating Voltage: 5V 
Linear motion: Motorized hybrid linear rails \& actuators

Scanning features:

Depth of field: $25 \mathrm{~mm}$

Maximum scanning depth using $\mathrm{Z}$ axis: $500 \mathrm{~mm}$

Distance to the target: $65-90 \mathrm{~mm}$

Maximum scanning area $(\mathrm{m} 2)$ : Only limited by storage capacity and structural frame

Scanning speed $(\mathrm{m} 2 / \mathrm{h}):$ ca. 0.25

Data features

File formats: 3D point cloud (RIS), 3D depthmap

(TIFF), 2D render (TIFF), raw video (AVI)

Point resolution: 10,000 points per $\mathrm{cm} 2$

Megabytes per m2: RIS (420 MB), 3D depthmap

32bit-TIFF (420 MB), 2D render 8bit-TIFF (88 MB), AVI (272 GB)

Software features Computer requirements: 3 USB 2.0 ports

Weight of the whole system: $53 \mathrm{Kg}$ 


\section{References}

ABDRABOU, A., Abdalla, M., Shaheen, I., Kamal, H., 2017 'The application of multispectral imaging and reflectance transformation imaging to an ancient Egyptian polychrome wooden stele' in ICOM-CC 18th Triennial Conference 2017 Copenhagen (2017)

AURE, X., O'Dowd, P., Padfield, J., 2017, Generating 3D Models of Paintings through the Combination of 2D, 3D and RTI Data, Available at: http://eprints.uwe.ac.uk/32398/1/AureODowd Padfield EVA2017.pdf

CHI (Cultural Heritage Imaging), 2013, Reflectance Transformation Imaging: Guide to Highlight Image Capture, Available at: http://culturalheritageimaging.org/What_We_Offer/Downloads/RTI_Hlt_Capture_Guide_v2_0.pdf [accessed 27 November 2016]

CHI (Cultural Heritage Imaging), 2014, Reflectance Transformation Imaging Glossary: Photographic and Technical Terms for RTI, Available at http://culturalheritageimaging.org/What_We_Offer/Downloads/Capture/CHI-RTI-Glossary_v1.pdf [accessed 15 December 2016]

HUGHES-HALLETT, M., 2016, The Applicability of Micro-RTI as a Tool for the Documentation and Conservation of Modern and Contemporary Paintings, unpublished research thesis, available apon request from the Conservation and Technology Department, Courtauld Institute of Art, London.

KOLKENA, L., Wijnberg, L., de Groot, E., Chavannes, M., 2017, 'Achrome (1960) by Piero Manzoni: An unpainted monochrome canvas: Research and treatment' in Zeitschrift für Kunsttechnologie und Konservierung vol. 31 (2017), 82-101

J. LAUFFENBURGER, E. K. Webb and P. Messier, "SEM vs. micro- Reflectance Transformation Imaging (RTI) for Examining Tool Marks," http://www.conservation-us.org/docs/default-source/annualmeeting/2015am_poster_75.pdf [accessed 5 May 2019]

FACTUM ARTE, Lucida: Discovering an artwork through its surface, available at: http://www.factum-arte.com/resources/files/fa/Lucida/manuals/2015 06 Lucida dossier_Eng.pdf [accessed 5 May 2019]

MALZBENDER, T., Gelb, D., and Wolters, H., 2001, 'Polynomial Texture Maps' in Computer Graphics, Proceedings of ACM Siggraph (2001), 519-528, Available at: http://www.hpl.hp.com/research/ptm/papers/ptm.pdf [accessed 17 October 2016]

MANFREDI, M., Bearman, G., Williamson, G., Kronkright, D., Doehne, E., Jacobs, M., and Marengo, E., 2014, 'A New Quantitative Method for the Non-Invasive Documentation of Morphological Damage in Paintings Using RTI Surface Normals' in Sensors 14:1227112284.

MESSIER, P., Johnson, R., Wilhelm, H., Sethares, W., Klein, A., Abry, P., Jaffard, S., Wendt, H.,Roux, S., Pustelnik, N., van Noord, N., van der Maaten, L., and Postma, E., 2013, 'Automated Surface Texture Classification of Inkjet and Photographic Media' in Technical Program and Proceedings: NIP29: The 29th International Conference on Digital Printing Technologies 85-91. 
MESSIER, P., 2014, Micro-RTI Capture (aka Monkey Brain): Software User Guide. Available at: http://media.wix.com/ugd/750e25_8de3df0e539f46b8b8eeb416388b2491.pdf [accessed 3 January 2017]

MUDGE, M., Malzbender, T., Shroer, C., and Lum, M., 2006, 'New Reflection Transformation Imaging Methods for Rock Art and Multiple-Viewpont Display' in The 7th International Symposium on Virtual Reality, Archaeology and Cultural Heritage VAST (2006) 195202.

MUDGE, M., Schroer, C., Earl, G., Martinez, K., Pagi, H., Toler-Franklin, C., Rusinkiewicz, S., Palma, G., Wachowiak, M., Ashley, M., Matthews, N., Noble, T., and Dellepiane, M., 2010, 'Principles and Practices of Robust, Photography-based Digital Imaging Techniques for Museums' in The 11th International Symposium on Virtual reality, Archaeology and Cultural Heritage VAST (2010) 111-137.

PADFIELD, J., and Saunders, D., and Malzbender, T., 2005, 'Polynomial texture mapping: a new tool for examining the surface of paintings' in Proceedings for ICOM 14th Triennial Meeting The Hague Preprints Vol. 1 (2005), 504-510.

PAYNE, E., 2012, 'Imaging Techniques in Conservation' in Journal of Conservation and Museum Studies 10 (2) 17-29.

Watteeuw, L., Hameeuw, H., Vandermeulen, B., Van der Perre, A., Boschloos, V., Delvaux, L., Proesmans, M., Van Bos, M., Van Gool, L., 2016. Light, shadows and surface characteristics: the multispectral Portable Light Dome. Appl. Phys. A Mater. Sci. Process. 122, 1-7. doi:10.1007/s00339-016-0499-4

\section{Author Biographies}




\section{Molly Hughes-Hallett}

Advanced Intern at the Hamilton Kerr Institute, University of Cambridge.

Molly is currently in her second year of an advanced internship at the Hamilton Kerr Institute, University of Cambridge. She graduated in 2017 with a post graduate diploma in the Conservation of Easel paintings from the Courtauld Institute of Art, London. In 2012 she completed her B.A in art history at Tufts University, Boston, and a B.F.A in painting and sculpture at the School of the Museum of Fine Arts, Boston. She has completed various internships and work placements at conservation studios in London. This paper is derived from her $3^{\text {rd }}$ year thesis project, completed at the Courtauld Institute of Art in 2016.

Contact:

Hamilton Kerr Institute,

Mill Lane,

Whittlesford,

CB22 4NE, UK

mh928@cam.ac.uk

\section{Christina Young}

Professor of Conservation and Technical Art History, Glasgow University.

Since 2017 Christina Young has been Head of the Technical Art History Group in the College of Arts at Glasgow University. She currently conducting research as Leverhulme Major Fellow on the history and significance of scenic art and artists in Great Britain; as well as running a Getty Conserving Canvas training project and applied conservation science projects . Christina has a BSc in Physics from Imperial College, London and an MSc in Applied Optics. In 1994 she was awarded the Gerry Hedley Research Scholarship and gained her PhD in the "Measurement of the biaxial tensile properties of paintings on canvas" in 1996. Before joining Glasgow University, she was a Reader in easel painting conservation and conservation science in the Conservation \& Technology Department, Courtauld Institute of Art. Prior to which she was Leverhulme Research Fellow at Tate Britain (1997-2000), a Getty Scholar at the Getty Conservation Centre, Los Angeles (2010).

Contact:

Head of Technical Art History

College of Arts

8 University Gardens

University of Glasgow

Glasgow, G12 8QQ

$\&$

Conservation Lab 2

The Hunterian at Kelvin Hall

Christina.young@glasgow.ac.uk

\section{Paul Messier,}

Pritzker Director, Lens Media Lab, Institute for the Preservation of Cultural Heritage, Yale University.

Paul Messier is the founder and Pritzker Director of the Lens Media Lab at Yale's Institute for the Preservation of Cultural Heritage. Established in 2015, the focus of the LML is the creation, dissemination, and interpretation of large datasets derived from museum and reference collections of artist materials. Notable among these is the LML's collection of historic photographic papers which is the largest of its kind in the world and was assembled 
by Paul over the course of decades. As founder of three private companies dedicated to cultural heritage preservation, Paul has published widely, holds two patents covering innovative techniques for the characterization of cultural materials, served elected terms to the Board of Directors of the American Institute for Conservation, and recently completed a multiyear Mellon-funded initiative to establish a department of photograph conservation at the State Hermitage Museum in Saint Petersburg, Russia. He holds a M.A. and Certificate of Advanced Study in the Conservation of Works on Paper from Buffalo State College, State University of New York and a B.A in art history from Vassar College.

Contact:

Yale University West Campus,

PO Box 27395 West Haven, CT 06516-7393 USA

Paul.messier@yale.edu 


\section{Figure captions}

1. Surface normal (red arrows) at a given point on a surface are perpendicular to the surface plane. The incident light angle is equal to the reflected angle in the relation to the surface normal. The RTI is created from these surface normal vectors. Diagram curtisy of CHI http://culturalheritageimaging.org/Technologies/RTI/

2. A) Incident light (yellow arrows) and reflected light (red arrows) are the same across the surface.

B) Due to the variation in the direction of surface normal, reflected light angles (red arrows) vary across the surface.

3. The micro-RTI system, rigged to a standing boom. Designed by Paul Messier.

4. A) RTI of test panel 2, default view showing intersection of two passages of paint.

B) RTI of test panel 2, specular view.

C) RTI of test panel 2, normal view.

5. A) Test panel 1 exhibiting friable blue pigment, micrograph illuminated from two points.

B) Test panel 1 with friable blue pigment, micrograph illuminated from the left raking light at approximately 45 degrees.

C) Test panel 1 with friable blue pigment, micrograph illuminated using angle light bar method at 20 degrees.

6. A) RTI of test panel 1 with friable blue pigment, default view.

B) RTI of test panel 1 with friable blue pigment, specular view.

C) RTI of test panel 1 with friable blue pigment, normals view.

7. A) RTI of test panel 3 before retouching, default view. Clearly showing the roughened texture from the vertical scratch.

B) RTI of test panel 3 before retouching, specular view.

C) RTI of test panel 3 before retouching, normals view.

D) RTI of test panel 3 after retouching, default view. Retouched using Paraloid B72 and dry pigments. While the colours match, the texture is clearly still unresolved.

E) RTI of test panel 3 after retouching, specular view.

F) RTI of test panel 3 after retouching, normals view.

8. Laser scan of test panel 6 , the image produced is of considerably lower quality than the RTI.

9. Friedrich Vordemberge-Gildewart, Composition No. 135, 1942, Oil on Canvas, 54 x 74 $\mathrm{cm}$, Yale University Art Gallery, Gift of Tom M. Schaumberg and Peter J. Schaumburg, 2010.139.1

10. A) RTI default view of Composition No. 135

B) RTI specular view of Composition No. 135

C) RTI normals view of Composition No. 135. The three diagonal incision lines are clearly visible, as are the specular difference between the matt and glossy paint passages.

11. Charles H. Parker A Full Pavilion at Surrey C.C.C The Oval, 1911, Oil on Canvas, wax lined, 170 x $302 \mathrm{~cm}$ (approx), Private Collection: Surrey County Cricket Club 
12. A) RTI specular view of A Full Pavilion at Surrey C.C.C The Oval. Showing the change in texture where the varnish and other surface coatings has been scratched away.

B) RTI normals view of A Full Pavilion at Surrey C.C.C The Oval

13. A) John Golding, Blue Predella, 1967, Acrylic on canvas, 228.6 x $165.1 \mathrm{~cm}$, John Golding Estate, on loan to the Courtauld Institute of Art. Location of the two dents described are indicated with black arrows.

14. A) Before treatment image of dent A on Blue Predella. taken using a conventional digital camera. The effectiveness of the treatment is clear through this photographic progression.

B) During treatment image of dent A on Blue Predella.

C) After treatment image of dent A on Blue Predella.

15. A) RTI default view of dent A on Blue Predella before treatment. The scratched surface texture can be seen in both specular and default views, as can the change in surface plane.

B) RTI specular view of dent A on Blue Predella before treatment.

C) RTI normals view of dent A on Blue Predella before treatment.

16. A) RTI default view of dent A on Blue Predella after treatment. The curved dent has been considerably reduced.

B) RTI specular view of dent A on Blue Predella after treatment.

C) RTI normals view of dent A on Blue Predella after treatment. 


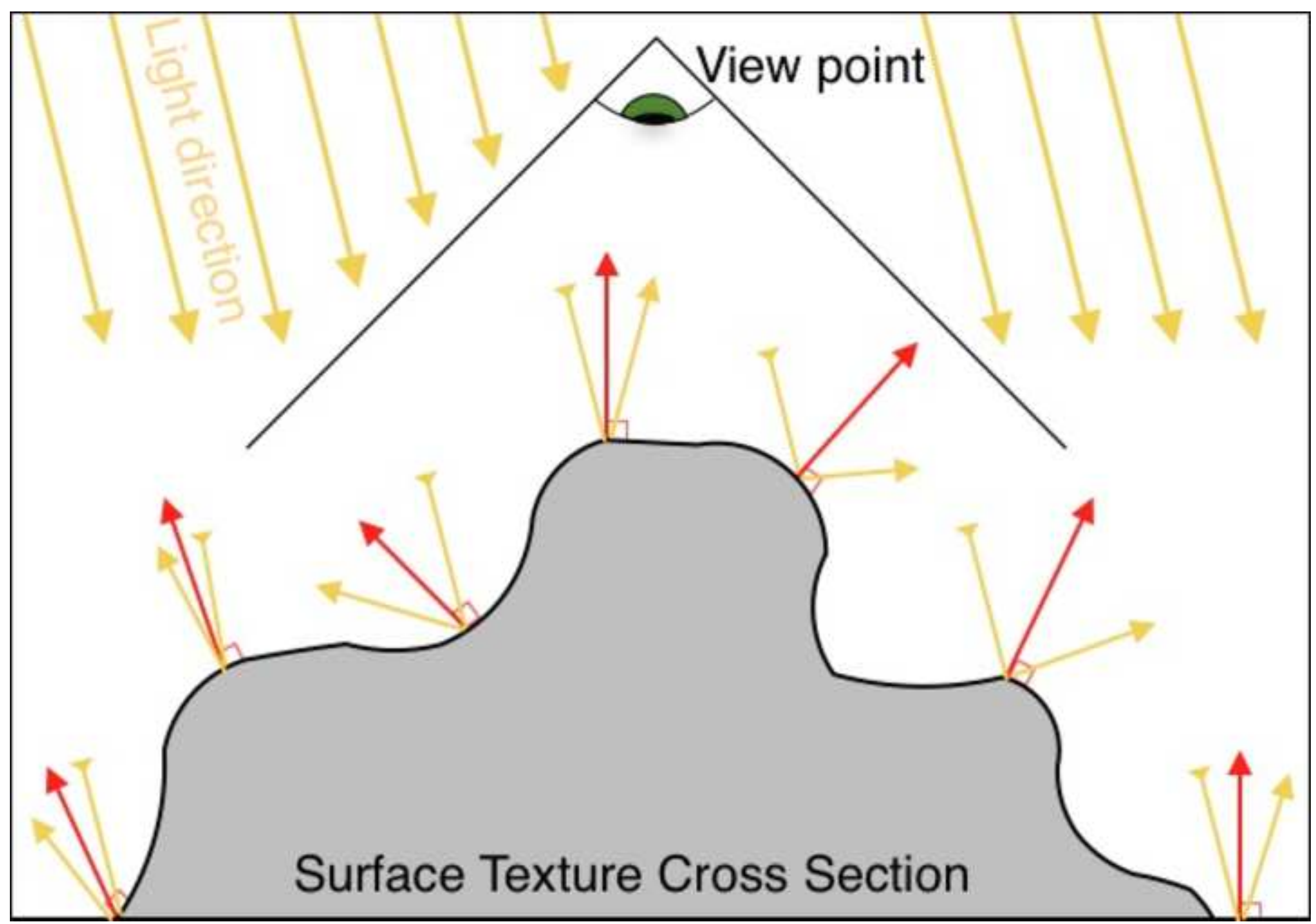




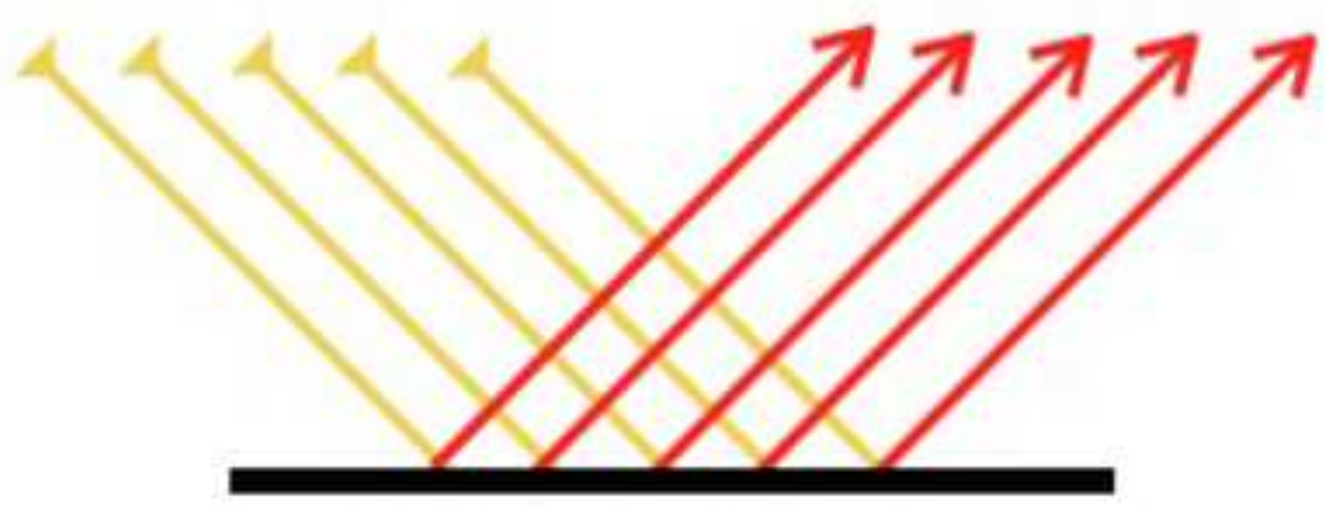

A. Specular Reflection (smooth surfaces)

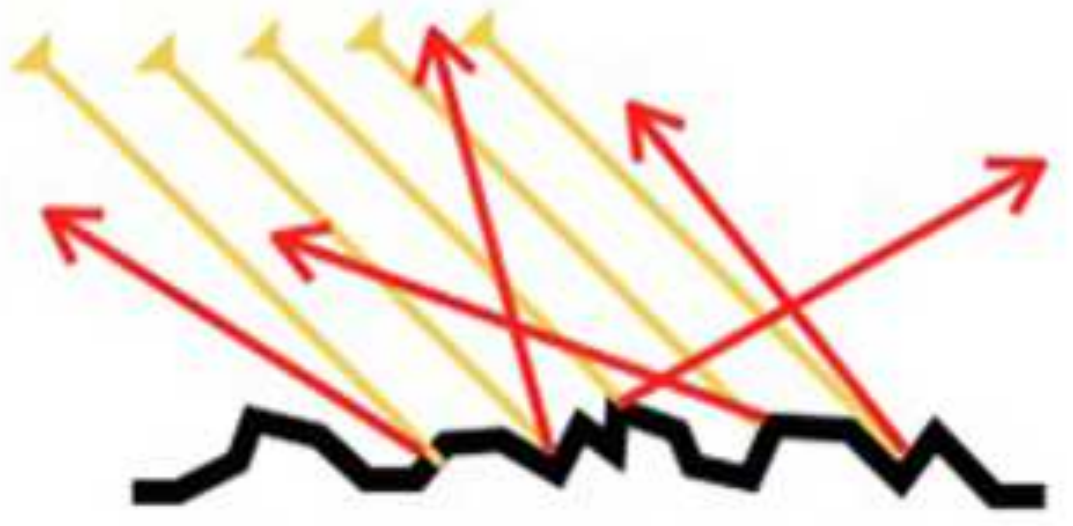

B. Diffuse Reflection (rough surfaces) 


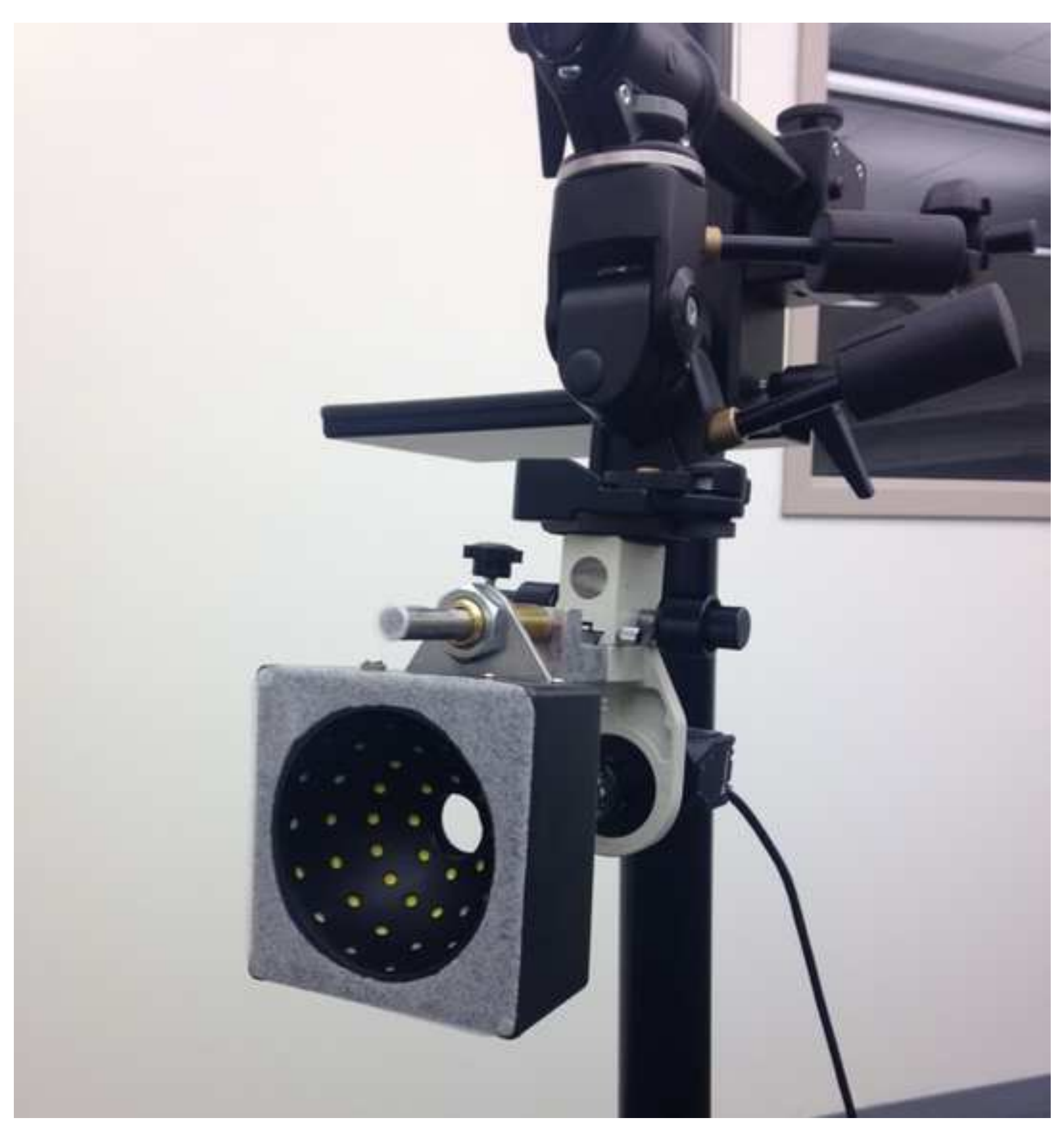


Click here to access/download;Figure;figure 4.jpg $\underline{\underline{ \pm}}$

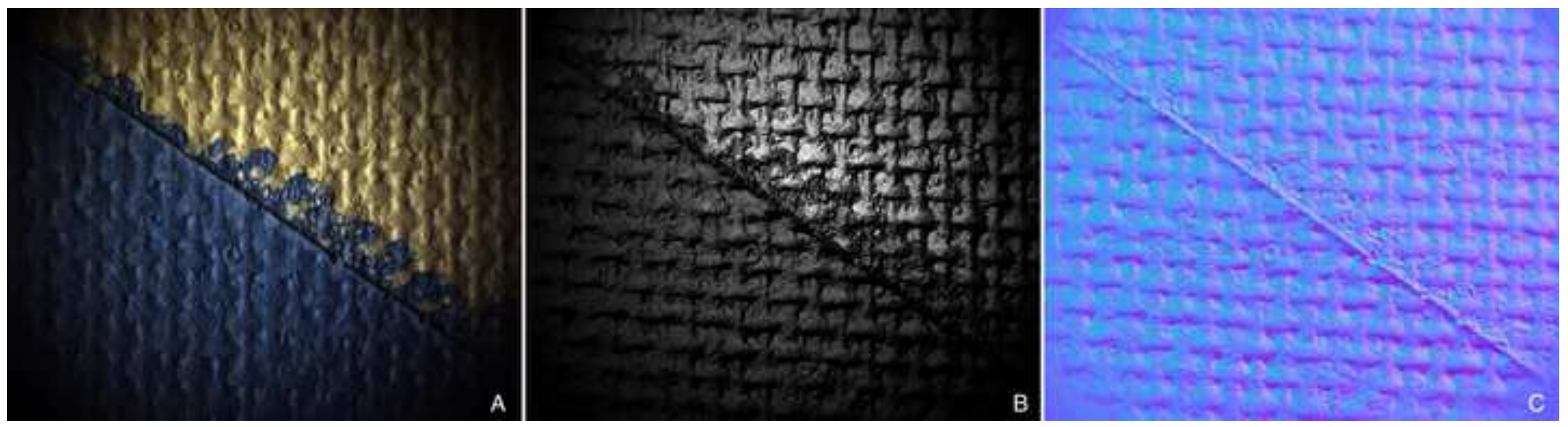




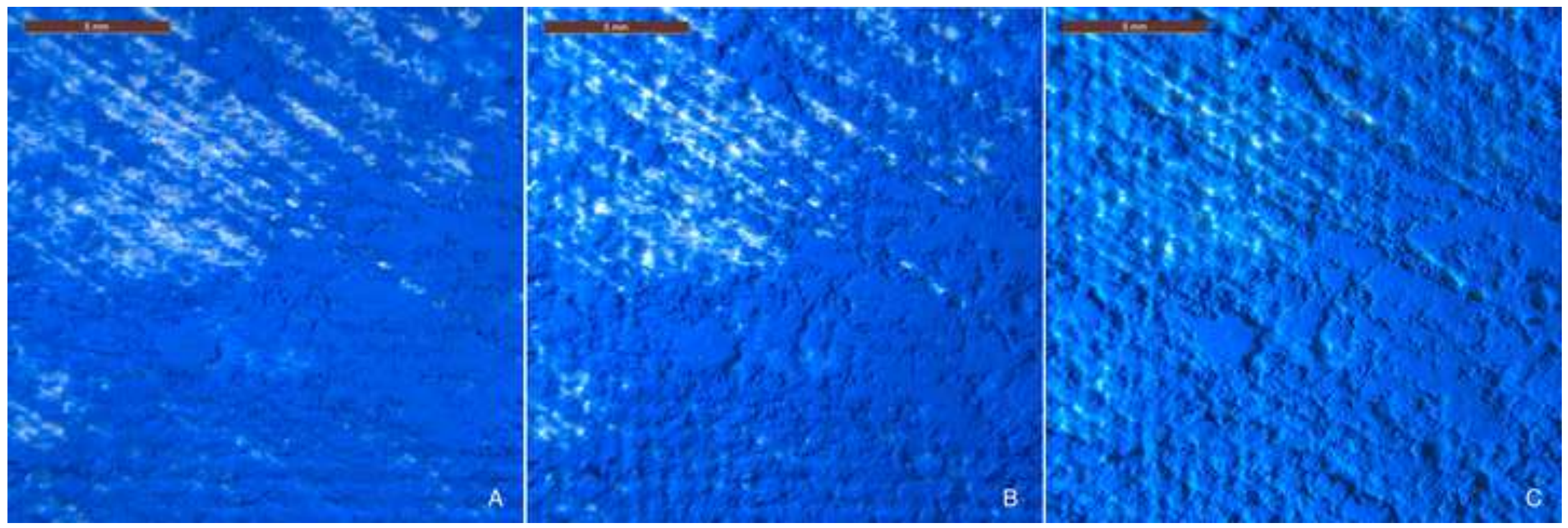


Click here to access/download;Figure;Figure 6.jpg $\underline{\underline{ \pm}}$
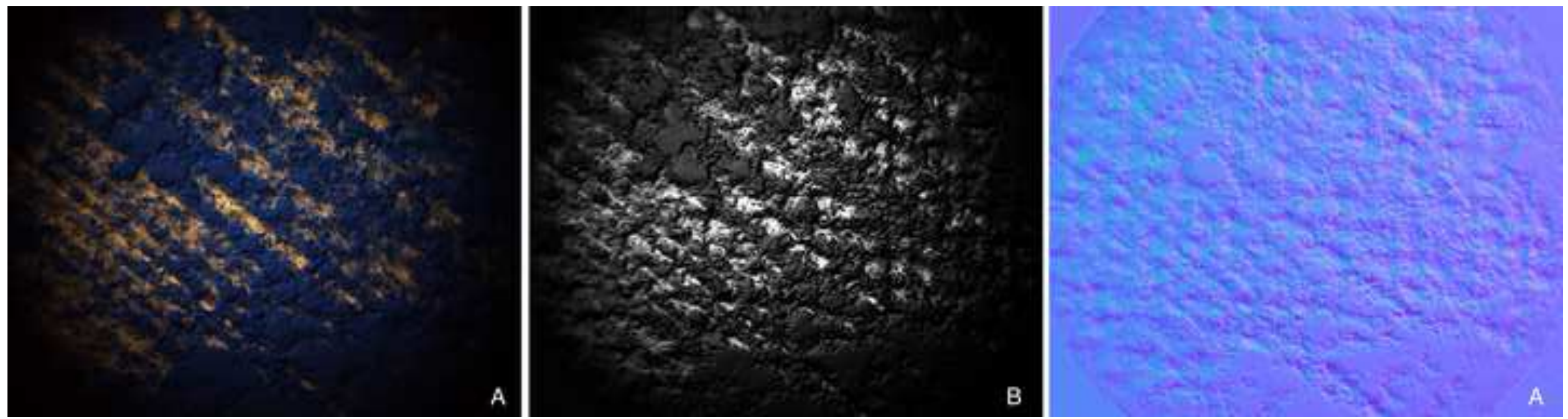

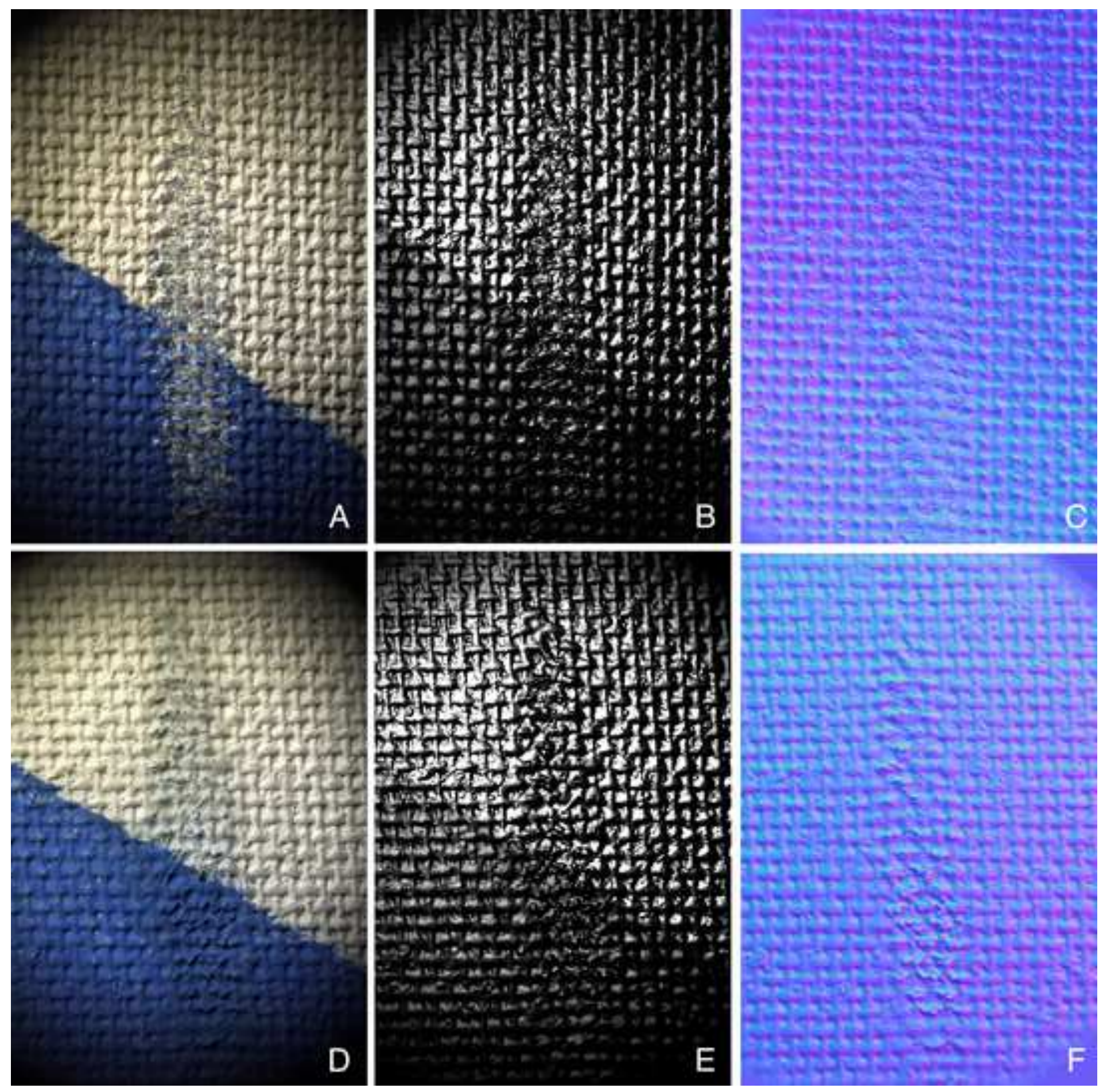

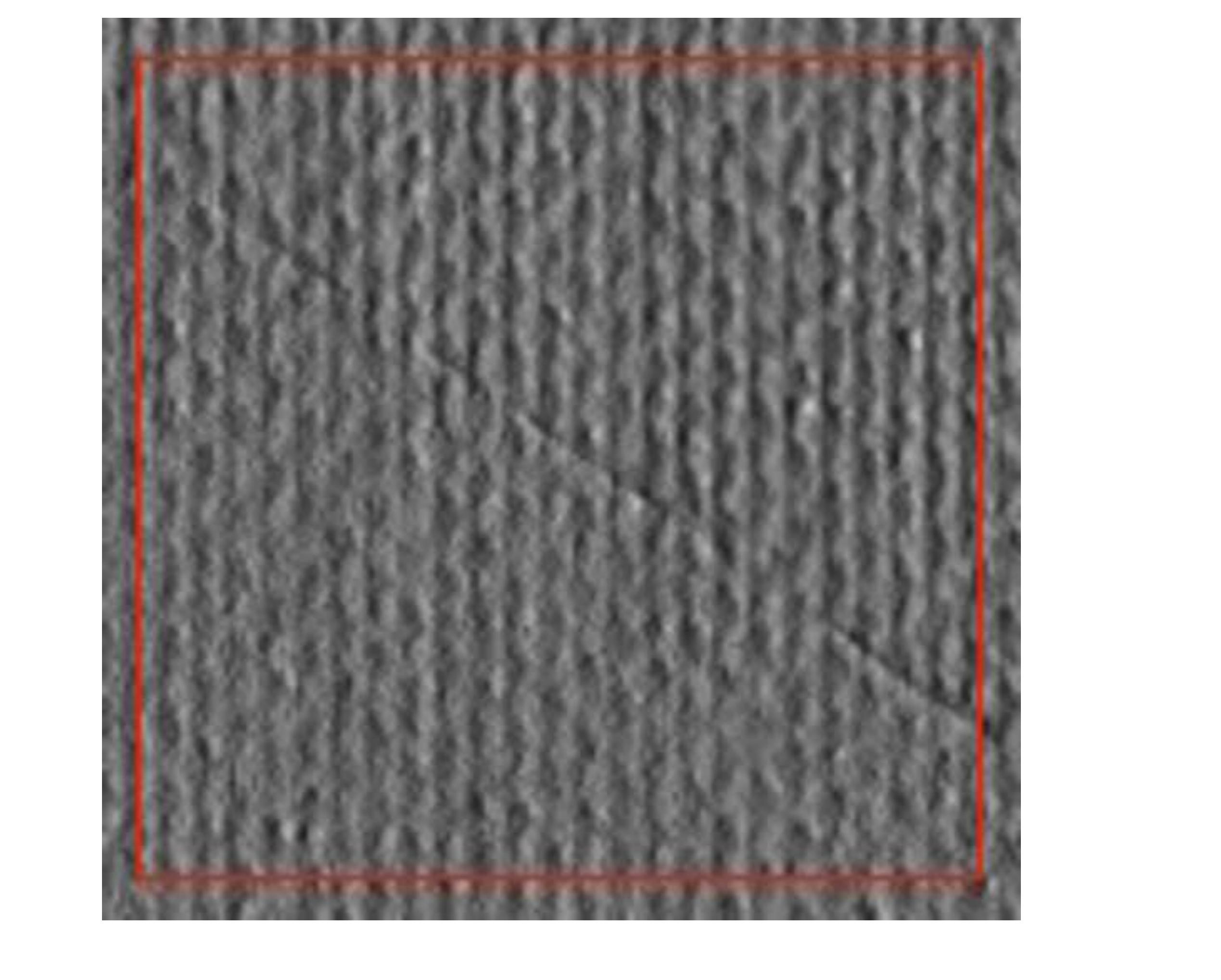

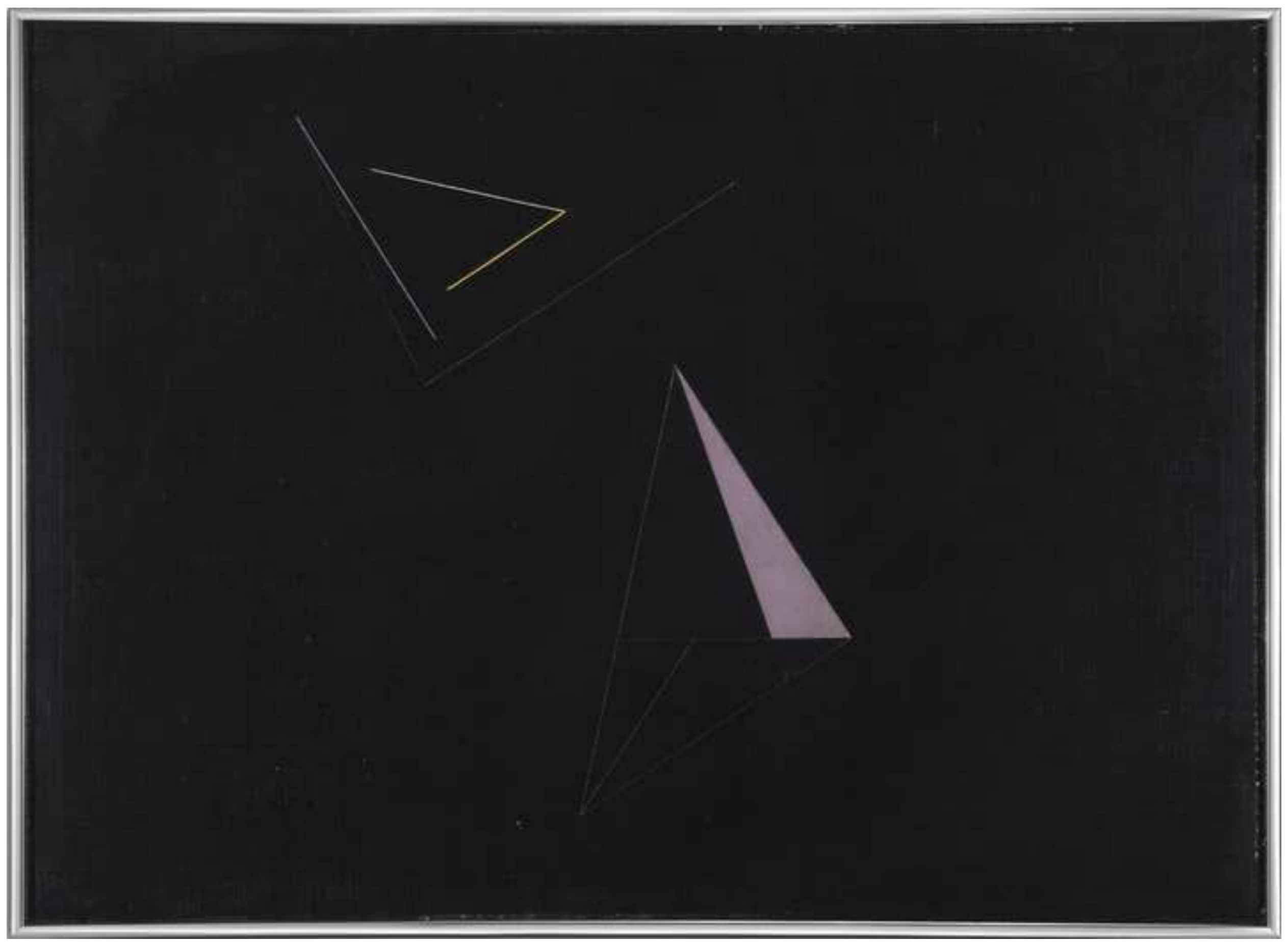

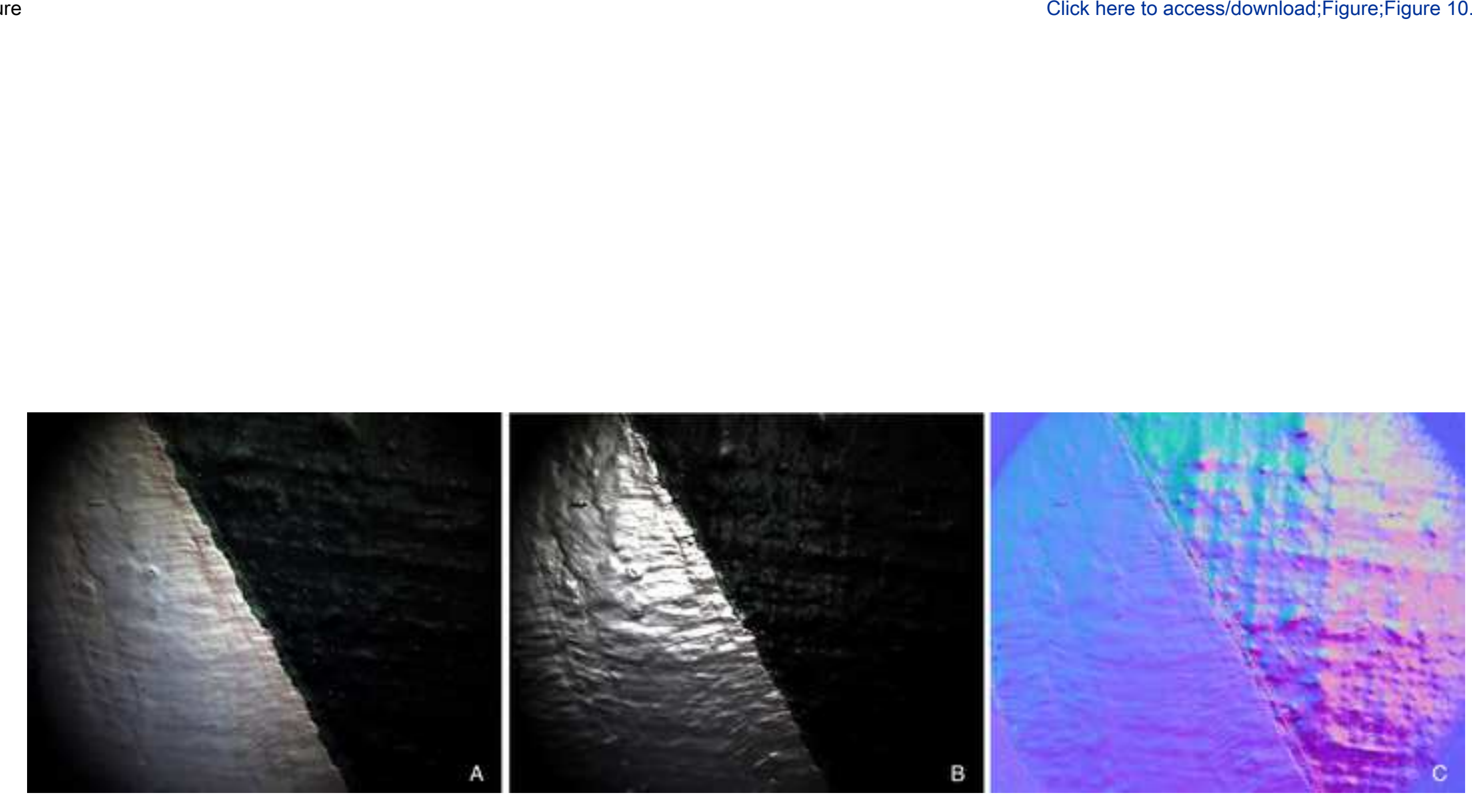

Click here to access/download;Figure;Figure 10.jpg $\underline{\underline{\underline{ }}}$
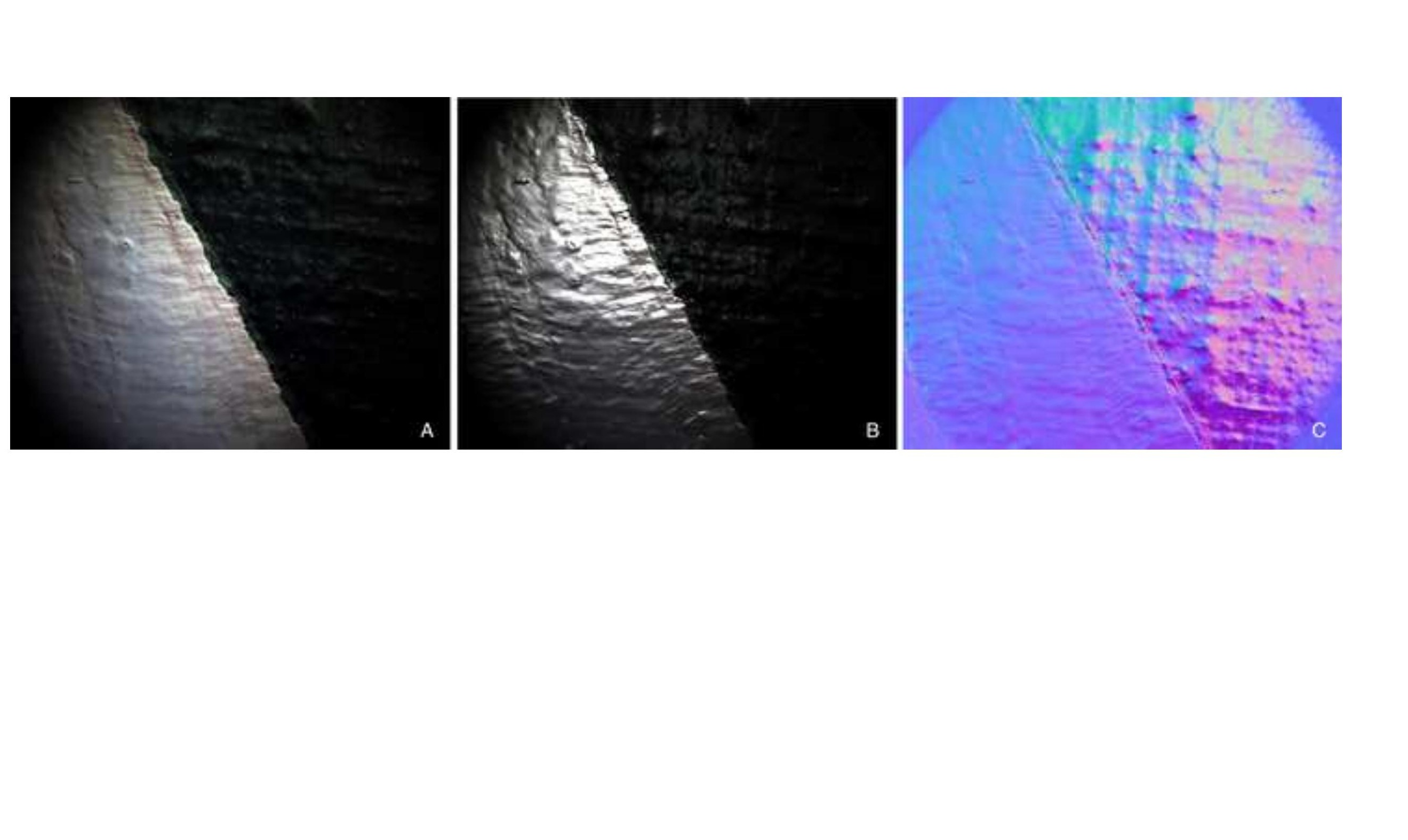


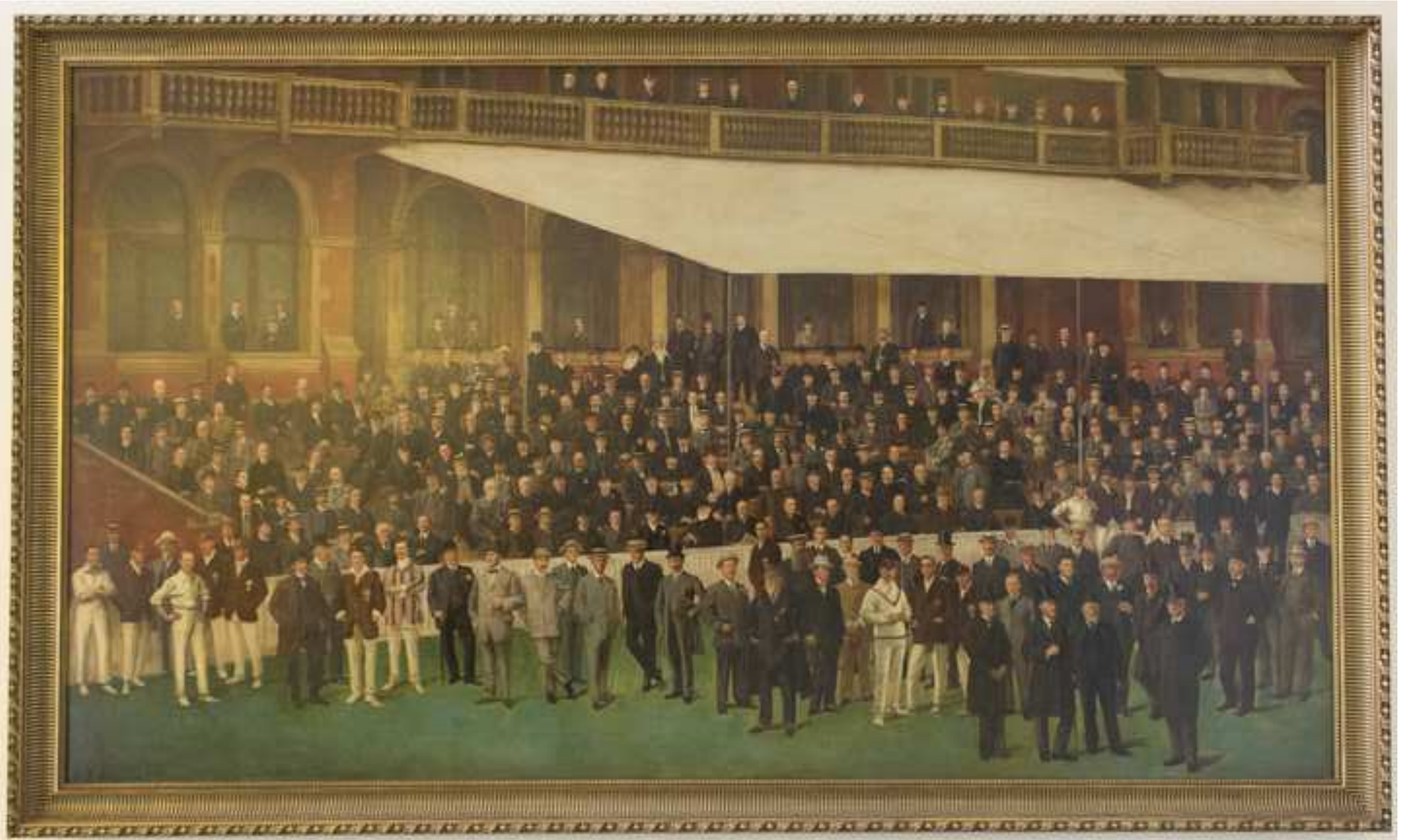

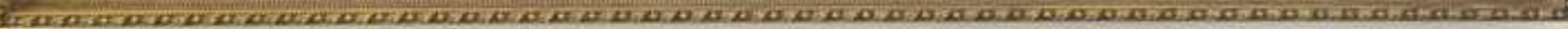


Click here to access/download;Figure;Figure 12.jpg $\underline{\underline{\Perp}}$
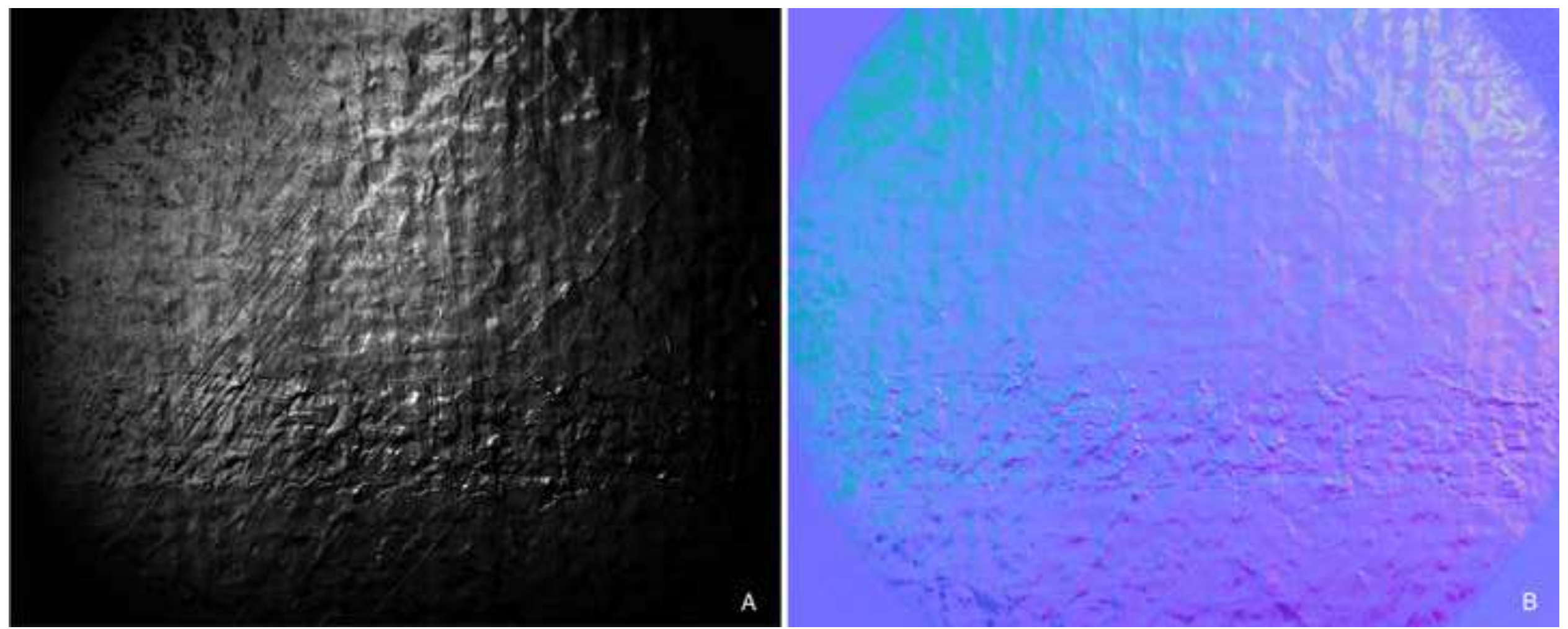


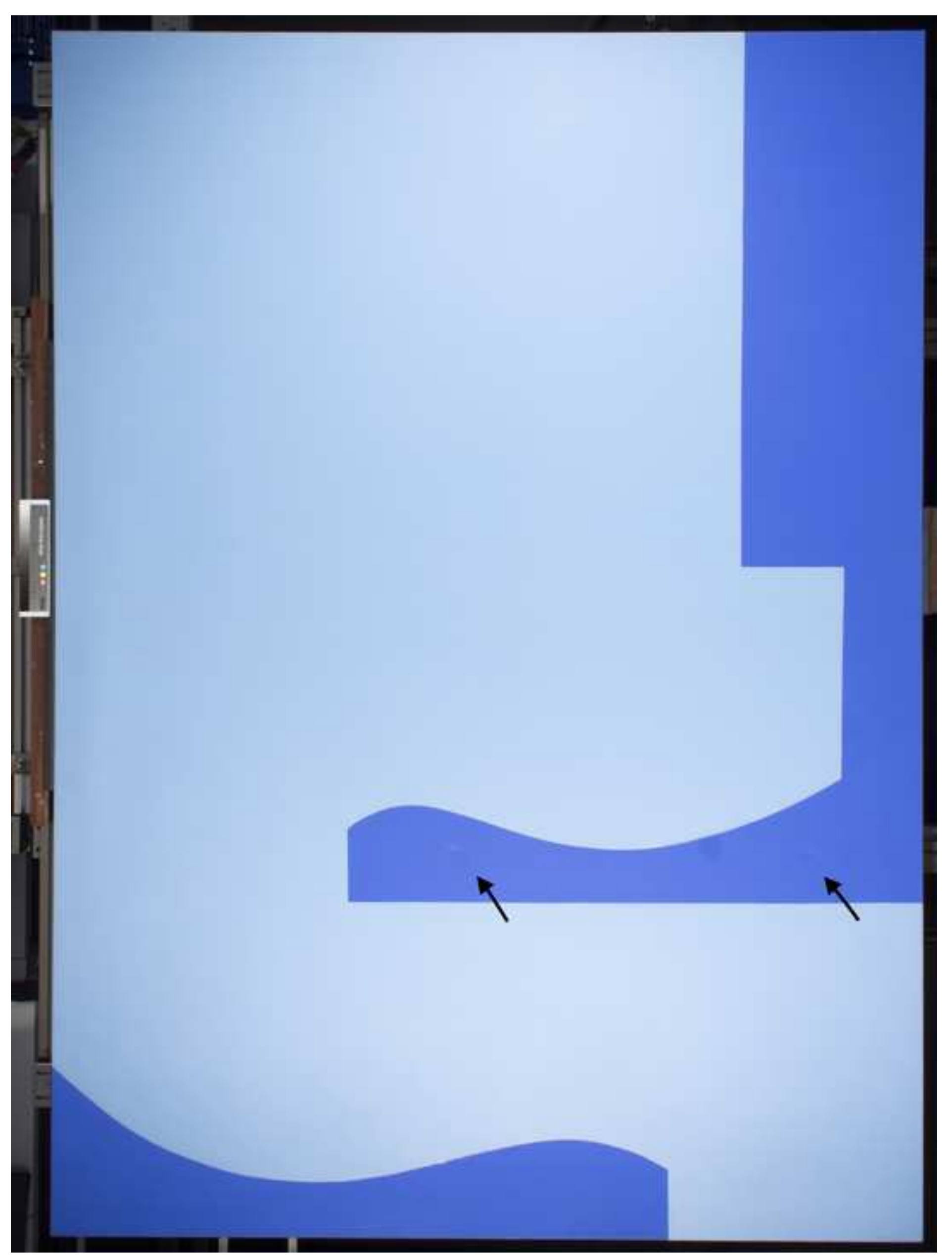

Click here to access/download;Figure;Figure 13.JPG $\triangleq$

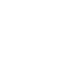



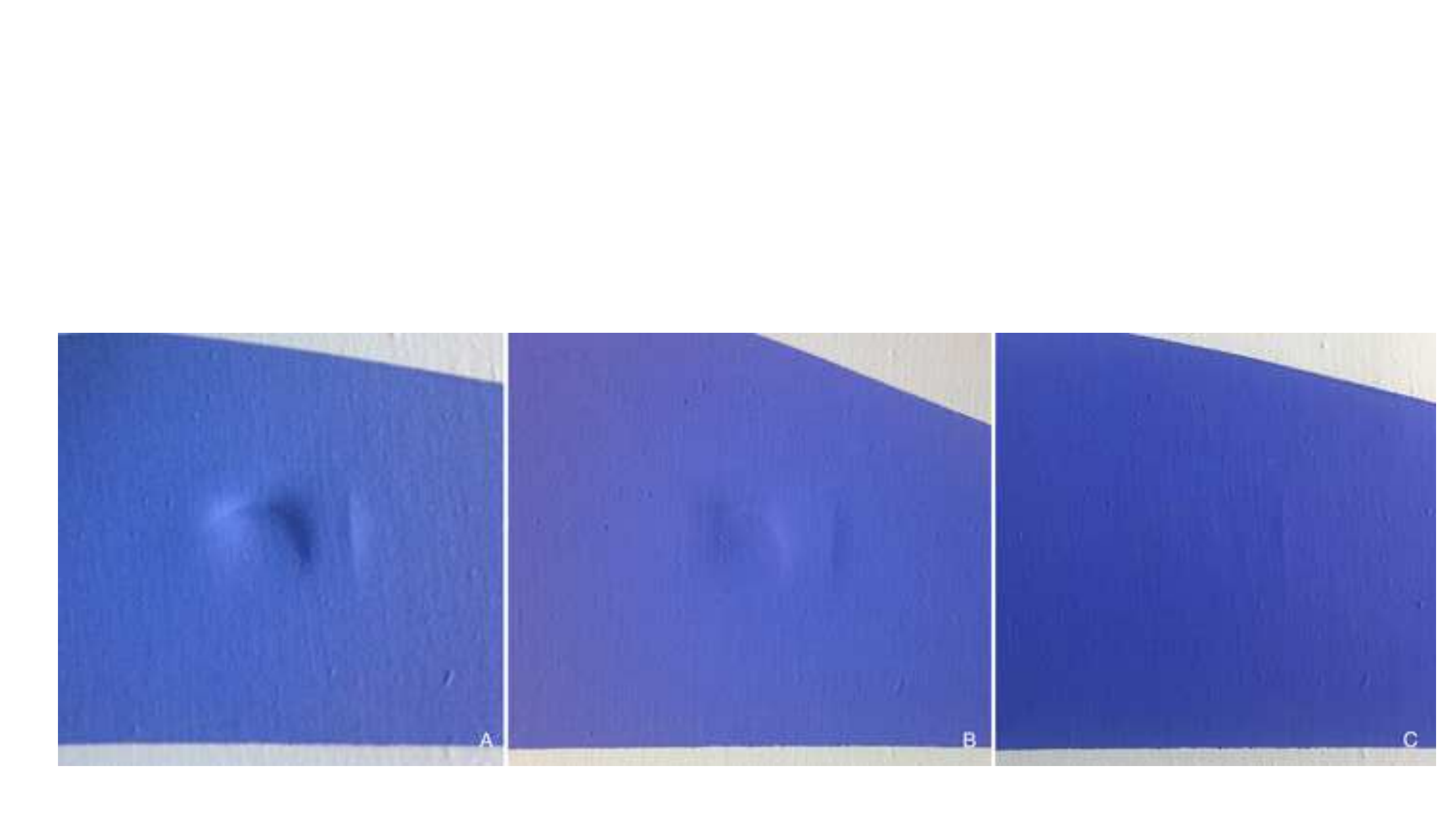

Click here to access/download;Figure;Figure 14.jpg \pm
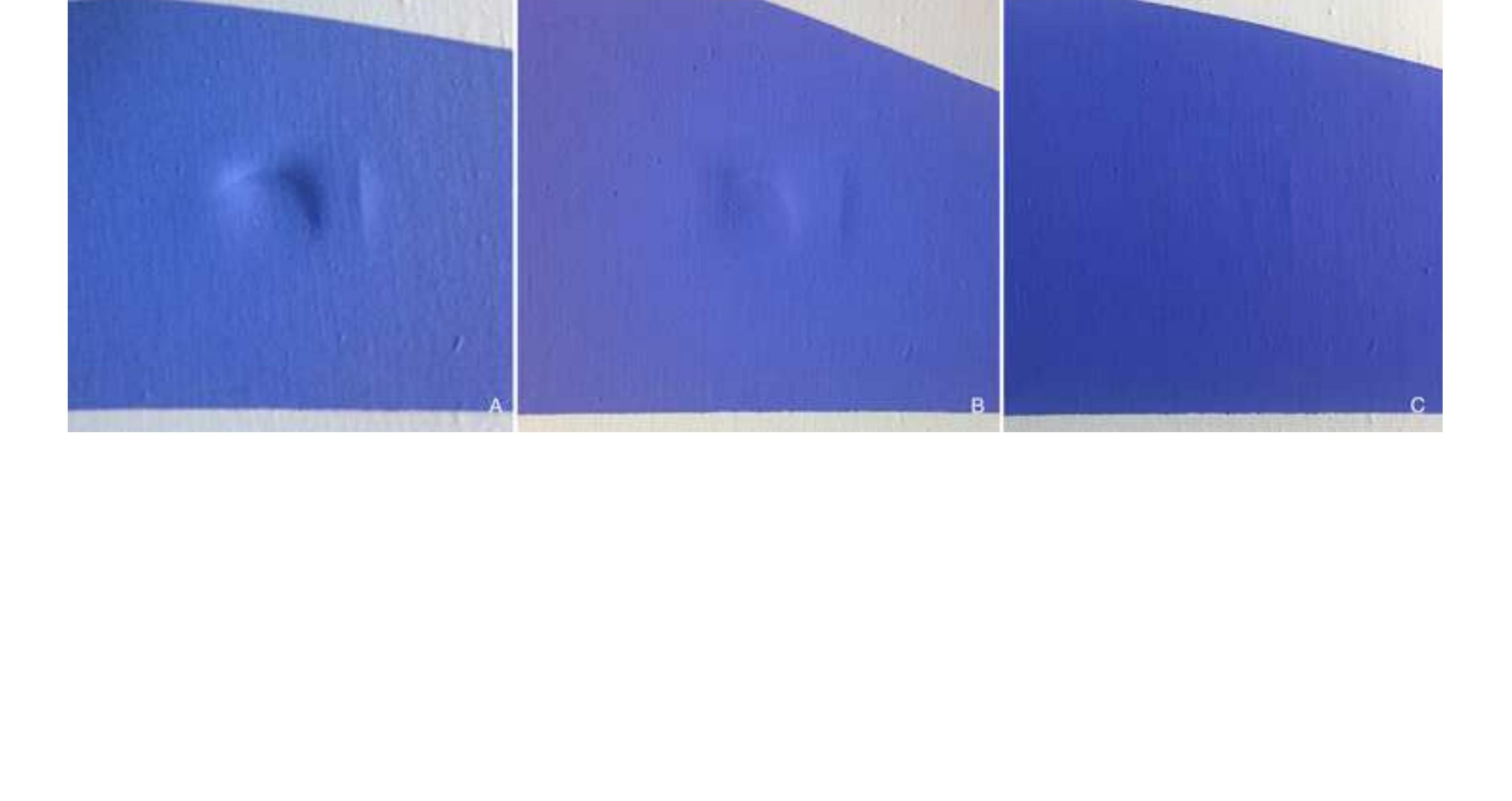

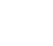




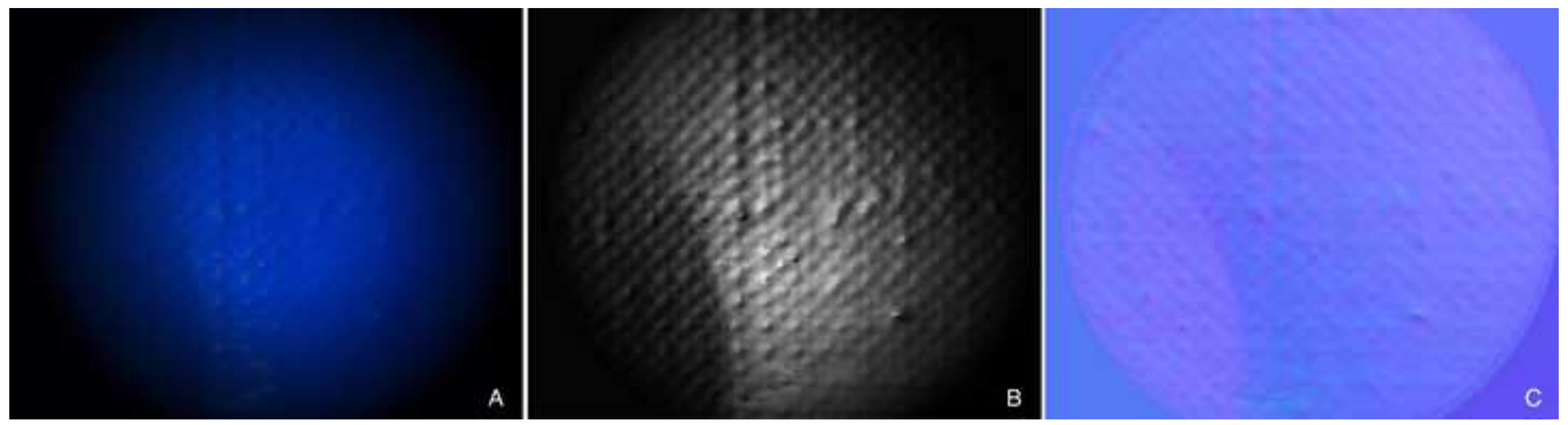


